\title{
Implementation of Digital Stereo Amplifier for Mobile IT Devices based on Wireless Communication System using Bluetooth
}

\author{
Joonhoon Park ${ }^{1}$, Ryumduck $\mathrm{Oh}^{* 2}$ \\ ${ }^{1}$ Dept. of Information \& Control Eng., Chungju National University \\ Chungju-si, Chungbuk-do, 380-702, Korea, jhpark@cjnu.ac.kr \\ * Corresponding Author \\ ${ }^{2}$ Dept. of Computer Science, Chungju National University \\ Chungju-si, Chungbuk-do, 380-702, Korea, rdoh@cjnu.ac.kr
}

\begin{abstract}
Bluetooth was started from concept that connected in all communication environments by single equipment integrating different communication devices. Wireless communications of today are using cellular phone, broadband wireless service, home $R F$, Bluetooth that supports data and voice and so on. Among these, Bluetooth is very useful wireless communication method. In this paper, a design and implementation method of wireless digital amplifier for mobile IT devices is presented.

Efficiency of analog amplifier is low and it has disadvantage that do not attach cooling fan by noise of inside. Moreover external form size of analog amplifier can't but be big because of heat sink. Therefore, analog amplifier is not suitable to mobile IT device. And today, it is trend that most IT devices that have wireless communication functions.
\end{abstract}

\section{Introduction}

Bluetooth forms ad-hoc network in extent within $10 \mathrm{~m}$. Also, both data and voice support. It is available worldwide because act in ISM wide-band. Transceiver made simplify selecting shaped, binary FM modulation system. Class-D amplifier amplifies digital signal using PWM(Pulse Width Modulation) method and then the amplified signal is reconstructed by analog signal using LPF(Low Pass Filter).

TPA3004D1/2 is Digital-to-Digital Converter(DDC) that change and amplifies in digital without flowing analog conversion to solve analog amplifier's problems[1]. The class-D amplifier can apply effectively to digital device etc. that seek downsize, high effectiveness, that power consumption because can achieve one-chip that mix various function inside interchange because heat occurs little when run. Power amplifier expands amplitude without fluctuation of frequency of input signal. And reason to use Bluetooth in connection with wireless communication, Bluetooth has market economic performance including various application profiles in specifications. $2.4 \mathrm{GHz}$ micro wave frequency of Bluetooth is appointed common frequency domain by ISM (Industrial, Scientific and Medical) band worldwide[2]. Service has been activated most recently among ISM frequency band of identical function at technology flow[3]. Bluetooth system supports point - to point connection and point-to-multi point connection[4]. Form networked by Bluetooth devices more than two call this as Pico net. It is Bluetooth's minimum unit and in distance within master surrounding about $10 \mathrm{~m}$ of one can connect same time to slave of maximum seven. Also, Scatter net is networking that composed connecting this Pico net.

\section{Bluetooth Connecting Procedure}

Pass through paging process to communicate between Bluetooth devices. Paging unit becomes Master in this connecting process $[5,6]$. And paged unit becomes slave. Master unit goes through the inquiry process while paging process. Master decides access code and frequency sequence from Slave unit's Bluetooth address data in this process (inquiry process). Connection situation acts by active, low power mode.

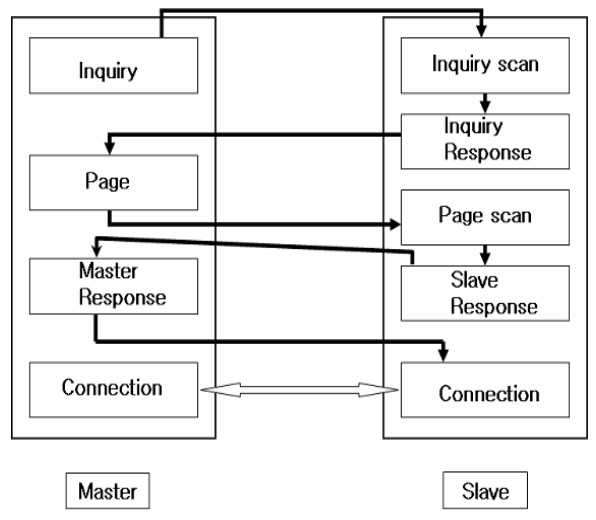

Figure 1. Bluetooth Connecting Process

\section{Communication Module Design}




\subsection{Hardware Design}

Block diagram of Fig. 2 that shows over is state after connection process between Bluetooth devices is made. Action progress process is as following. Preferentially, send specification sign from keypad of module 1(Transmit unit). This sign does arithmetic, transaction in CPU. Then transmit data through Bluetooth by receive unit.

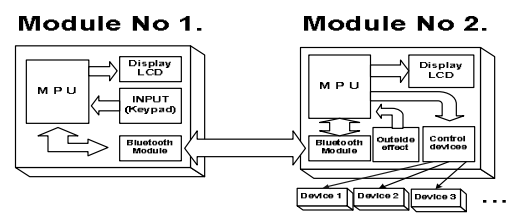

Figure 2. Block diagram of Bluetooth system

CPU sends received data. And each controlled object device is controlled and managed through CPU. Also, embodied wireless communication module can check situation of module adversely.

\subsection{Software Design}

Fig. 3 is Transmit unit's algorithm that talks action progress order of module(Transmit unit).

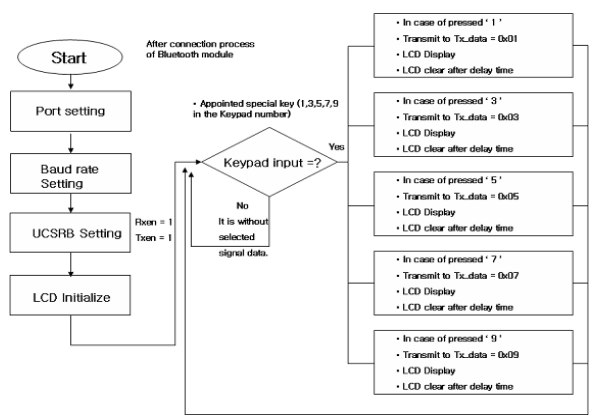

Figure 3. Transmit Unit Module

Fig. 4 is Receive unit's flow chart that talks action progress order of module(Receive unit).

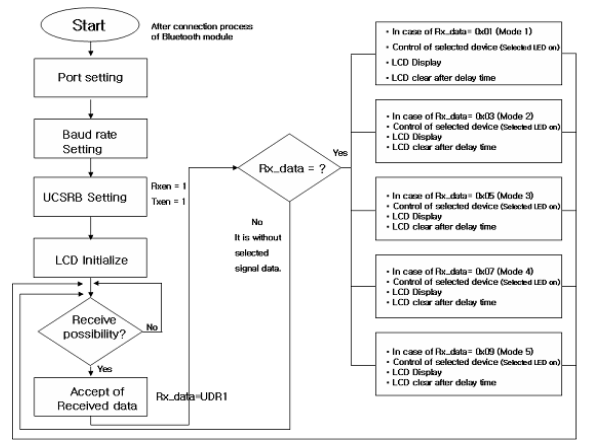

Figure. 4 Receive Unit Module

\subsection{Experimentation}

For the experimentation, we design and embody the system hardware and software as shown in Fig. 2. This experimentation did a wireless communication system test to use Bluetooth manufactured hardware for the mobile IT devices.

\subsubsection{Data transmission error rate}

Specification key of Transmit Unit Module sends fixed data by CPU. Then, CPU transmits data through Bluetooth. Transmitted data is passed RS-232C cable through Bluetooth and sends by PC. Transmitted data confirms the data error rate to use hyper terminal program. Above process measured particularly the data error rate by each distance/baud rate.

Table 1. Results of data transmission error rate

\begin{tabular}{|c|c|c|c|c|c|c|c|c|}
\hline \multicolumn{3}{|c|}{ Distance } & \multicolumn{6}{|c|}{$480 / 9600 / 19200$ Baud Rate } \\
\hline \multirow[b]{2}{*}{4800} & \multirow[b]{2}{*}{9600} & \multirow[b]{2}{*}{19200} & \multirow{2}{*}{\begin{tabular}{|l|} 
Character \\
TU - PC \\
\end{tabular}} & \multirow{2}{*}{\begin{tabular}{|l|} 
Sentence \\
TU - PC \\
\end{tabular}} & \multirow{2}{*}{$P C-T U$} & \multirow{2}{*}{$\begin{array}{l}\text { Is either-way } \\
\text { communication } \\
\text { available? }\end{array}$} & \multicolumn{2}{|c|}{ Note } \\
\hline & & & & & & & $\mathrm{BT}$ & DT \\
\hline 0 30m & $0 \sim 30$ & $0 \sim 30$ & $100 \%$ & $100 \%$ & $100 \%$ & a & & \\
\hline $31 \sim 49 \mathrm{~m}$ & $31 \sim 44$ & $31 \sim 45$ & $100 \%$ & $100 \%$ & $100 \%$ & 0 & Short & Hardly \\
\hline $50 \sim 60 \mathrm{~m}$ & $45 \sim 60$ & $46 \sim 60$ & $100 \%$ & $100 \%$ & $100 \%$ & 0 & & \\
\hline 61 69m & 61 67 & 61 64 & $100 \%$ & $100 \%$ & $100 \%$ & 0 & Little & Little \\
\hline $70 \mathrm{~m}$ & 68 & 65 & $100 \%$ & $100 \%$ & $100 \%$ & 0 & Long & Long \\
\hline $71 \mathrm{~m}$ & 69 & 6.6 & $\begin{array}{r}\text { Recognit } \\
\text { Blu }\end{array}$ & ion disable & $\begin{array}{l}\text { between } \\
\text { ices }\end{array}$ & $x$ & & vibility \\
\hline
\end{tabular}

As shown in Table 1, there was delay time, recognition time according to distance. But, confirmed high data accuracy in case of recognized between Bluetooth modules. When it is indoor ( $78 \mathrm{~m}$ section) that wireless LAN is established, was shown maximum that can communicate for 4800 bps - $75 \mathrm{~m}, 9600 \mathrm{bps}-77 \mathrm{~m}$, 19200 bps - $71 \mathrm{~m}$. High accuracy was seen in data accuracy with upside. According to the results of comparison between the infield test data and indoor test data, we can examine that the difference of communication distance is affected by the minimization of outside electronic wave interference of building block.

\subsubsection{Bluetooth recognition time}

\section{1) Case 1: Open field}

Occasion of 4800 bps: Section that module control is available, maximum recognition section is possible to $60 \mathrm{~m}$. Also, stable and fast recognition time was seen to section ago $50 \mathrm{~m}$. Occasion of 9600 bps: Very unstable recognition was seen in $55 \mathrm{~m}$ and $41 \sim 50 \mathrm{~m}$ section was shown abnormal recognition time. Stable and fast recognition section is $40 \mathrm{~m}$.

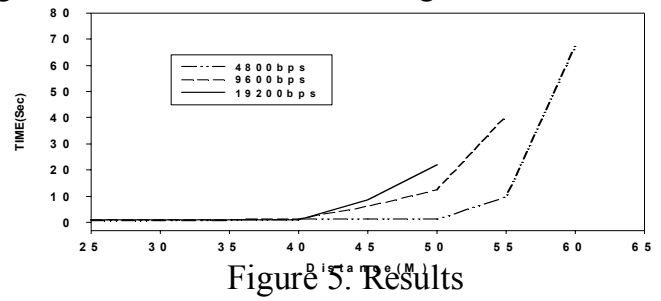

Occasion of 19200 bps: Maximum recognition section was $50 \mathrm{~m}$ and did not recognize in more section. 
2) Case 2 : Indoor (Without wireless LAN facility)

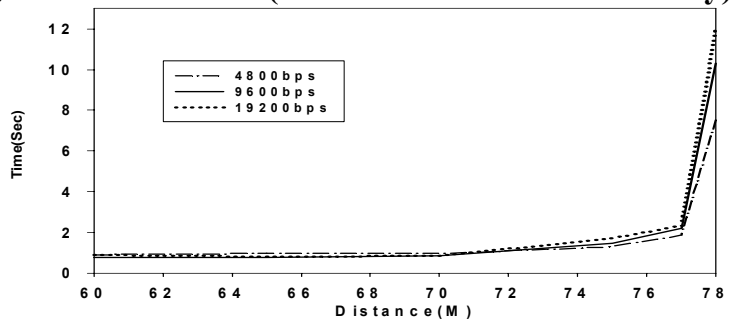

Figure 6. Results

As shown in Fig. 6, confirmed that become recognition between Bluetooth devices as is stable and fast in section ago $70 \mathrm{~m}$. Recognition time between Bluetooth devices was changed from $77 \mathrm{~m}$ sections by each baud rate change. It could know which recognition between devices is unstable from this section seeing this.

\section{3) Case 3: Indoor(With wireless LAN facility)}

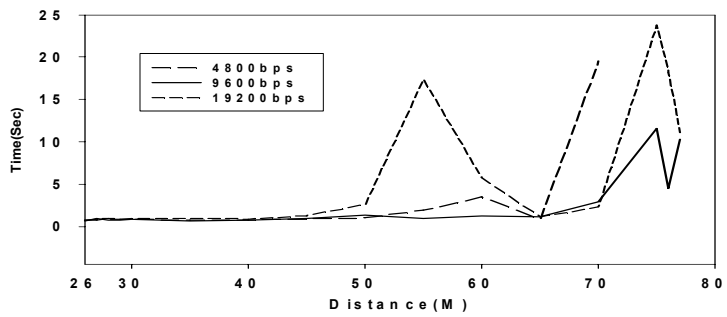

Figure 7. Results

Occasion of 4800 bps: $50 \mathrm{~m}$ previous sections could see early recognition time. Know uncertainty static recognition in $51 \sim 70 \mathrm{~m}$ section. It was impossible recognition since $70 \mathrm{~m}$. Occasion of 9600 bps: Stable and fast recognition time was seen in $45 \mathrm{~m}$ previous section. Later in section, uncertainty static recognition $(77 \mathrm{~m}, 78 \mathrm{~m}(5$ $\sim 10 \%$ (1 2th/ 20th)) do or recognition was impossible. Occasion of 19200 bps: Was stable in 40m previous section but abnormal recognition time was seen to $41 \sim 77 \mathrm{~m}$. Recognition was impossible from $78 \mathrm{~m}$ sections. The results are shown in Fig. 7.

\section{Digital Amplifier}

\subsection{Classification of Digital Amplifier}

The amplifier can divide class according to topology of output stage and judge electrical property by efficiency, distortion factor, linearity, THD(Total Harmonic Distortion) etc. Even if class-A amplifier is no sign or load while there is no cross over THD, a lot of electric currents are passed and happen by heat. Do not pass over maximum efficiency $25 \%$. These are arranged in Table 2.

Table 2. Classification of digital amplifier

\begin{tabular}{|c|c|c|c|}
\hline Class Type & $\begin{array}{c}\text { Theoretical } \\
\text { Value (\%) }\end{array}$ & $\begin{array}{c}\text { Practical } \\
\text { Value (\%) }\end{array}$ & Advantage \\
\hline Class-A & 50 & $25-50$ & Highest Linearity \\
\hline Class-B & 78.8 & $50 \sim 70$ & High Linearity \\
\hline Class-AB & 78.5 & $50 \sim 70$ & $\begin{array}{c}\text { Highest Linearity than } \\
\text { Class-B }\end{array}$ \\
\hline Class-D & 100 & 90 & Highest Efficiency \\
\hline
\end{tabular}

\subsection{Class-D Amplifier}

Class-D amplifier is displaying near efficiency for $100 \%$, and characteristic of frequency response is superduper, and there are advantages that distortion factor and noise is less[2]. Amplified PWM signal is changed and is displayed by analog signal flowing output LPF before is displayed in speaker as shown in Fig. 8 and 9.

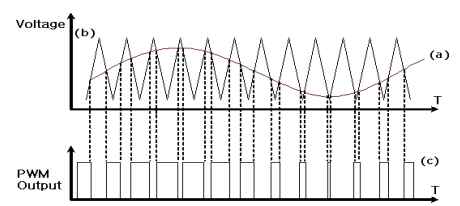

Figure 8. Generating PWM signal

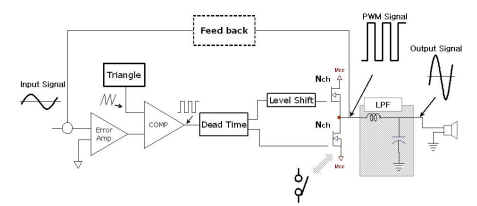

Figure 9. Block diagram of class-D amplifier

\subsection{Design of Digital Stereo Amplifier}

In this paper, designed digital stereo amplifier to use TPA3004D1/2 of TI that have output of $20[\mathrm{~W}]$ and achieved dynamic characteristic improvement work such as PCB pattern noise analysis to improve performance of the amplifier. Circuit schematic diagram is designed using CSiEDA's WINPCB which is electronic circuit design tool for designed digital amplifier. Fig. 10 is schematic diagram of digital amplifier that use TPA3004D2 of DDC mode.

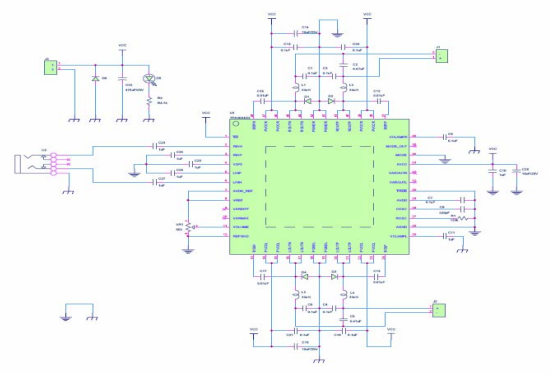

Figure 10. Schematic diagram of digital stereo amplifier

Because of this point, must design circuit pattern maximum shortly. 3D PCB pattern diagram about schematic diagram using 3D function offering in design 
tool is shown in fig. 11 There is advantage that $3 \mathrm{D}$ PCB composition can remove problem that can happen in assembly process by assembling PCB to cyber in the advance.
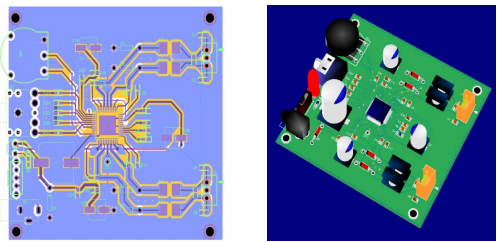

Figure 11. 3D design for PCB pattern

\section{4 Prototype Model}

Model of digital stereo amplifier is designed using Pro/Engineer Wildfire. Designed model of 3D digital amplifier by Wildfire as take advantage of 3D data that create through CSiEDA and is seen to Fig. 12.
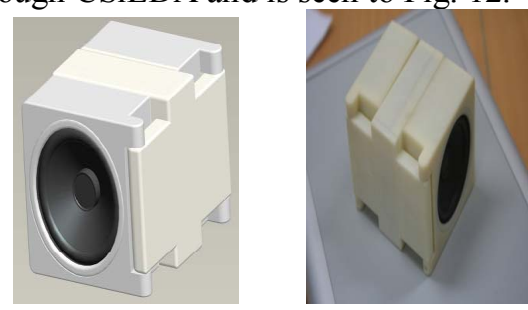

Figure 12. 3D design of prototype model and its mock-up

\subsection{Experimentation: Digital Stereo Amplifier}

Designed schematic diagram and manufactured PCB circuit board, and executes performance test including noise test of implementation system. Measured waveform before and after inductor application of output stage for this, tested performance of digital amplifier that is manufactured by measuring output signals about various input signal. Measured noise improvement availability by inductor using input signal of $20 \mathrm{KHz}$ as shown in Fig. 13.
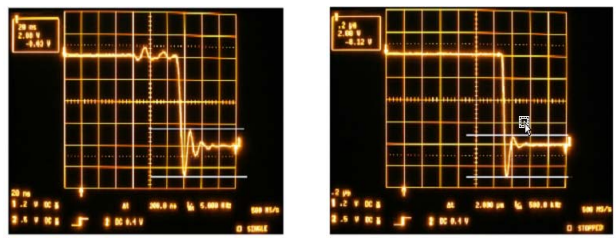

Figure 13. Before(a) and after(b) of applying inductor

In (a) of Fig. 13 with in case of did not apply inductor ringing phenomenon of $4.2[\mathrm{~V}]$ appear, but when applied inductor with (b) of Fig. 13, could know that ringing phenomenon decreased by $3.6[\mathrm{~V}]$. Therefore, in this paper, applied inductor to reduce this ringing phenomenon, and wished to lay length of pattern shortly by maximum and decrease effect of outside noise.
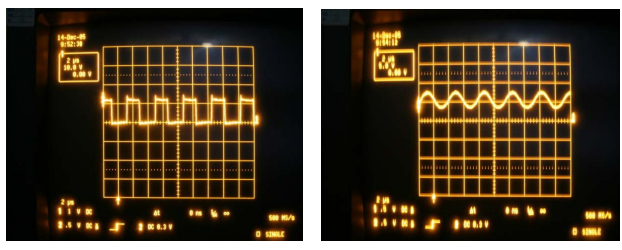

Figure 14. PWM waveform and reconstructed waveform

Fig. 14 is PWM conversion waveform of digital stereo amplifier about song sound source as input and measures amplification waveform that is reconstructed by analog signal again.

\section{Conclusions}

We can design and implement remote control system using Bluetooth simply, but we can expand and utilize the design method to various applications such as ubiquitous networking platform, wireless and mobile IT devices and etc. Furthermore, Bluetooth can be used in long distance wireless communication such as the RF communication by increase of antenna gain and electric According to the recognition time test, we can realize that Bluetooth is affected and interfered by wireless LAN and magnetic field such as microwave.

The wireless class amplifier is designed and implemented using TPA3004D2 and Bluetooth chipset. As the results of data transmission test, data error rate shows zero under the given conditions. Also, communication is available by most stabilize and fast awareness in section within $30 \mathrm{~m}$.

\section{References}

[1] J. W. Lee, J. S. Lee, G. S. Lee: "A 2 W BTL single-chip class-D power amplifier with very high efficiency for audio applications," Circuits and System Proceedings, ISCAS 2000 Geneva, The 2000 IEEE International Symposium, vol. 5, pp. 493-496, 2000.

[2] J. H. Park, Y. G. Choi, S. D. Jang: "Design and implementation of high efficiency class-D amplifier using TPA3001D1", Journal of KIIT, vol. 5, No 1, pp181-187 , 2007.

[3] S. H. Park: "Noise technology for electronic circuits ", Kukje Technoinfo Lab., 2003.

[4] "Bluetooth technology connection", http://www.Handy wave.com/index $2 / \mathrm{html}, 2001$.

[5] S.H. Park, A Bluetooth system design technology, Techno Press, Seoul, 2002.

[6] B. Gehring and S. Koutroubinas, "Design of cableless devices with the Bluetooth Specification", http:// www.csdmag.com/main /2000/02/0002 blue.htm. 